\title{
Toxicity of a Trumpet Shell Charonia sauliae ("Boshubora") Inhabiting along the Coasts of Miyazaki Prefecture
}

\author{
Tamao NoguchI, ${ }^{* 1}$ Tadashi Sakal, ${ }^{* 2}$ Junichi Maruyama, ${ }^{* 1}$ \\ Joong Kyun JeON, ${ }^{* 1}$ Kuraki KesAmaru, ${ }^{* 2}$ \\ and Kanehisa HaSHIMOTO*1
}

(Accepted September 25, 1984)

\begin{abstract}
A total of 375 specimens of a trumpet shell Charonia sauliae ("boshubora") were collected from September 1982 through May 1984, from the following eight places in Miyazaki Prefecture: Kitaura (12 specimens), Urashiro (122), Yasui (24), Akamizu (122), Tsuno (22), Aoshima (24), Oshima (5), and Kushima (44). Digestive glands were excised from these specimens and examined for toxicity by an official assay method of tetrodotoxin.

Seventy-two out of the 375 specimens $(19 \%)$ were toxic, with the highest toxicity of $106 \mathrm{MU} / \mathrm{g}$ in the digestive gland. The frequency of toxic specimens varied between 0 and $55 \%$, depending upon the place of collection. It was found that this shell as a whole is less toxic in Miyazaki Prefecture than in other prefectures so far screened.

Out of the four specimens of a starfish Astropecten polyacanthus ("togemomijigai") collected at Urashiro and Kushima, three were toxic (the highest toxicity score $18 \mathrm{MU} / \mathrm{g}$ for the whole body), suggesting its involvement in toxification of the trumpet shell.
\end{abstract}

Two food poisoning cases have so far been reported which are associated with ingestion of a trumpet shell Charonia sauliae ("boshubora"): one in Shizuoka Prefecture") in December 1979 and the other in Wakayama Prefecture') in December 1982. In both cases, the causative agent was identified later as tetrodotoxin which was supposed to have come from a starfish Astropecten polyacanthus ("togemomijigai") by the food chain. ${ }^{2,3}$

This species of trumpet shell is widely distributed along the Pacific coasts of southwestern Japan. Tetrodotoxin is a potent neurotoxin, posing continuously a serious problem in food hygiene. These situations aroused us to survey the toxicity of the trumpet shells inhabiting the coasts of Miyazaki Prefecture. The results obtained showed that the trumpet shells are toxified in Miyazaki Prefecture as well, though at a lower level than those from other prefectures so far reported.
Charonia sauliae ("boshubora") were collected at eight places in Miyazaki Prefecture in September 1982 through May 1984 (Fig. 1). The specimens were caught mostly by a trawling net, and some by a gill net for lobster or diving.

Four specimens of a starfish Astropecten polyacanthus ("togemomijigai") were also collected at Urashiro and Kushima.

The trumpet shell and starfish specimens thus collected were kept frozen below $-20^{\circ} \mathrm{C}$ until assayed for toxicity.

\section{Assay of Toxicity}

Each trumpet shell specimen was partially thawed, and the digestive gland was removed and examined for toxicity by the official assay method of tetrodotoxin.4) In the case of starfish, the whole body was subjected to toxicity assay similarly.

"Toxic" specimens were defined here to be $\geqq 2 \mathrm{MU} / \mathrm{g}$ digestive gland (trumpet shell) or $\geqq 5$ MU/g whole body (starfish).

\section{Materials and Methods}

\section{Materials}

\section{Results and Discussion}

A total of 375 specimens of the trumpet shell Out of the 375 trumpet shell specimens collected,

*1 Laboratory of Marine Biochemistry, Faculty of Agriculture, The University of Tokyo, Bunkyo, Tokyo 113, Japan (野口玉雄・ 丸山純一・銭 重均・橉本周久: 東京大学農学部水阵化学研究室).

*2 Faculty of Agriculture, Miyazaki University, Funatsuka-3, Miyazaki 880, Japan（境 正 - 妿㓋丸会基： 宮岟大学農学部). 


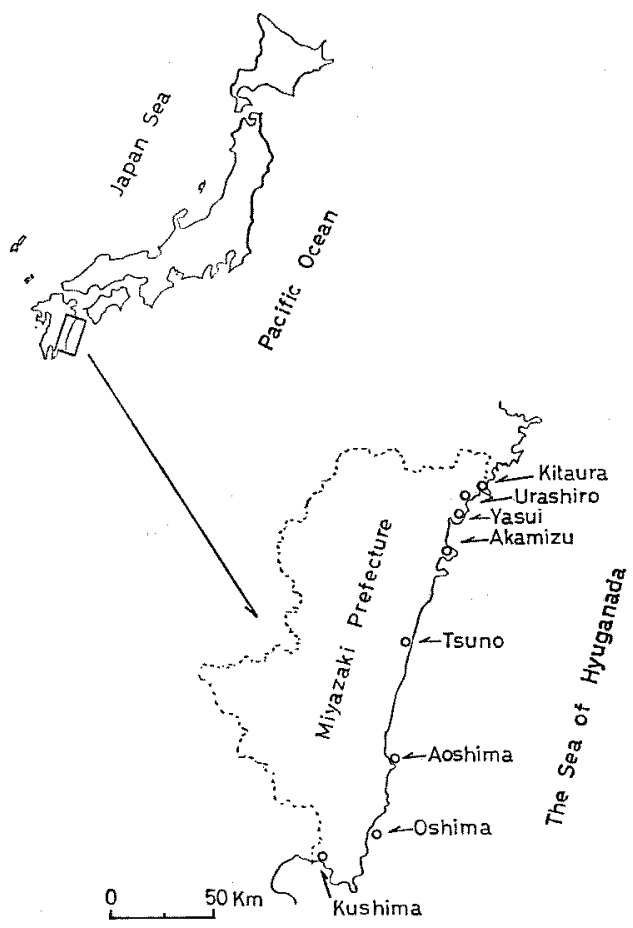

Fig. 1. Map showing the sampling places of trumpet shell.

72 were found to be toxic (Table 1). The frequency of toxic specimens was calculated to be $19 \%$ on an average. However, the frequency varied from 0 to $55 \%$, depending upon the place of collection. For example, all the specimens at Yasui were non-toxic, whereas at Akamizu, a nearby place, about $1 / 4$ the total specimens was found to be toxic (Fig. 1 and Table 1).

The average toxicity of all the specimens assayed was calculated to be $3.6 \mathrm{MU} / \mathrm{g}$ digestive gland, assuming for convenience that the toxic scores of all the non-toxic specimens were zero. The highest was recorded at Aoshima (12.5 MU/g digestive gland), followed by Kushima (7.6 MU/g) and Akamizu (5.2 MU/g).

The highest toxicity detected was $106 \mathrm{MU} / \mathrm{g}$ digestive gland of an Aoshima specimen. The total toxicity of this one was roughly calculated to be $5,300 \mathrm{MU}$, which is approximately one half of the lethal dose of tetrodotoxin in human being.

Eight to twenty-one specimens were collected monthly throughout a year at Urashiro, and assayed for toxicity. The results showed that the trumpet shells here were mostly non-toxic except winter months (February and March) when some toxic specimens were detected with the highest score of $17 \mathrm{MU} / \mathrm{g}$ digestive gland.

Size-dependency of the toxicity was not clear, since even the specimens of comparable sizes collected at the same place in the same season exhibited wide variations in toxicity (Fig. 2).

As far as the present data are concerned, the frequency of toxic specimens, along with the toxicity level of the trumpet shell, is significantly lower in Miyazaki Prefecture than in several other prefectures so far screened: e.g., the frequency of toxic specimens and the highest toxicity recorded being $95 \%$ and $1,950 \mathrm{MU} / \mathrm{g}$ digestive gland, respectively, in Shizuoka Prefecture ${ }^{1)} ; 68 \%$ and $480 \mathrm{MU} / \mathrm{g}$, respectively, in Wakayama Prefecture $^{2)}$; and $69 \%$ and $460 \mathrm{MU} / \mathrm{g}$, respectively, in Mie Prefecture.*3

On the other hand, three out of the four starfish

Table 1. Toxicity of trumpet shell specimens collected at eight places in Miyazaki Prefecture

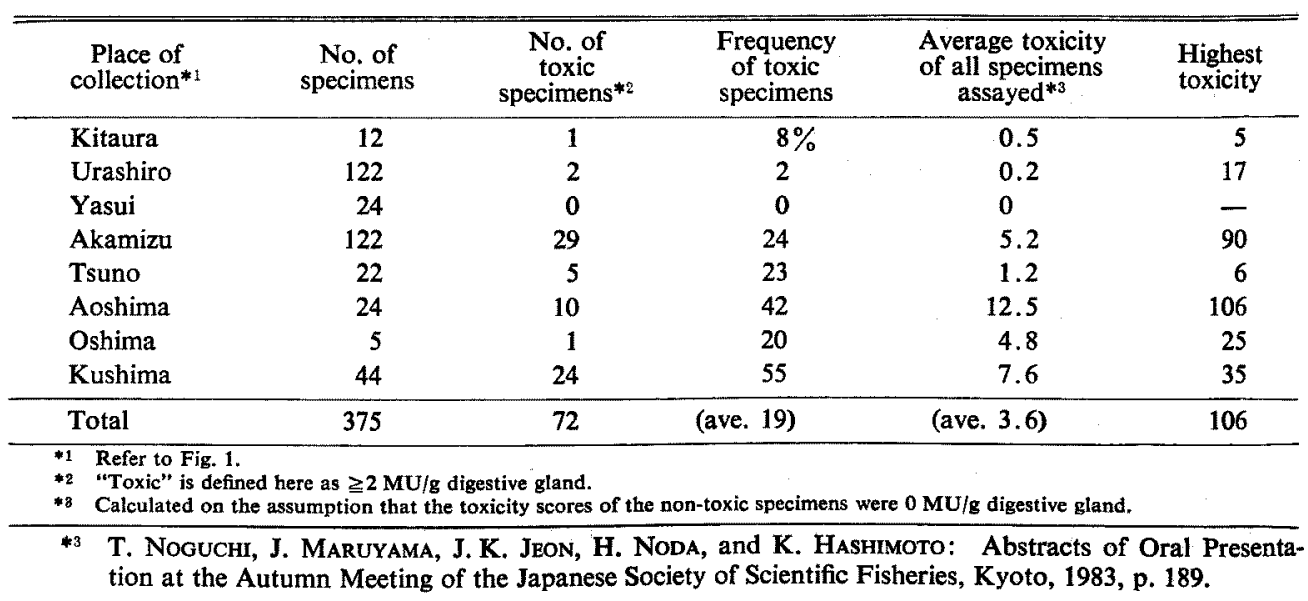




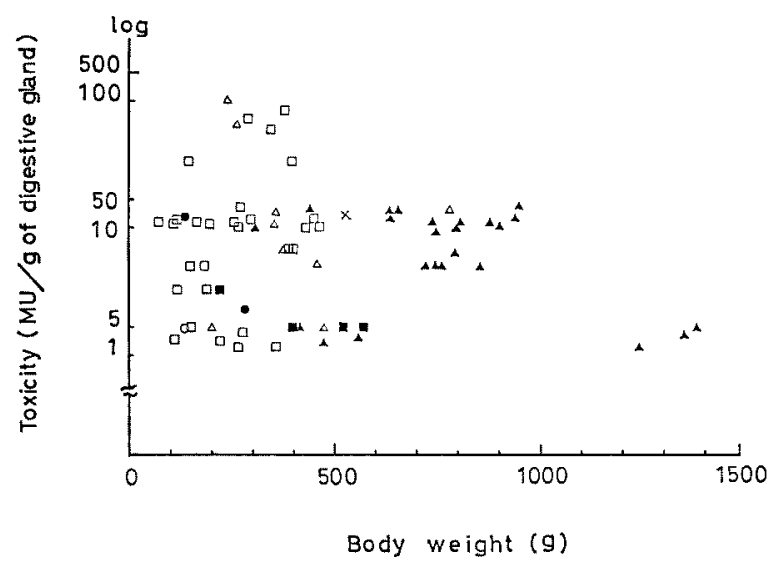

Fig. 2. Toxicity scores of trumpet shell specimens in function of their body weights: $O=$ Kitaura, - =Urashiro, $\square=$ Akamizu, $\mathbf{E}=$ Tsuno, $\Delta=$ Aoshima, $\Delta=$ Kushima, $x=$ Oshima.

specimens collected were found to be toxic. The highest toxicity recorded was $18 \mathrm{MU} / \mathrm{g}$ whole body. This suggests that the starfish is involved in toxification of the trumpet shell here.

Further screening of toxicity is needed on the trumpet shells inhabiting the coasts of Miyazaki Prefecture.

\section{Acknowledgements}

We express our sincere thanks to $\mathrm{Mr}$. $\mathrm{K}$. Hidaka, Miyazaki University, and Mr. H. YanAGIDA and the staff of Fisheries Division, Miyazaki Prefectural Government, for collecting the trumpet shell specimens assayed. This work was supported in part by a Grant-in-Aid from the Ministry of Education, Science and Culture.

\section{References}

1) H. Narita, T. Noguchi, J. Maruyama, Y. Ueda, K. Hashimoto, T. Watanabe, and $K$. HidA: Bull. Japan. Soc. Sci. Fish., 47, 935-941 (1981).

2) J. Maruyama, T. Noguch, J. K. Jeon, K. YAMAZAKI, and K. Hashimoto: J. Food Hyg. Soc. Japan., 24, 465-468 (1983).

3) T. Noguchi, H. Narita, J. Maruyama, and $K$. Hashimoto: Bull. Japan. Soc. Sci. Fish., 48, 1173-1177 (1983).

4) Environmental Health Bureau, Ministry of Health and Welfare (ed.): Food Hygiene Examination Manual, Vol. 2, Japan Food Hygiene Association, Tokyo, 1978, pp. 232-240. 